\title{
Metabolic Syndrome Is Associated with Atrial Electrical and Mechanical Dysfunction
}

\author{
Hale Yilmaz ${ }^{a}$ Kazım Serhan Özcan ${ }^{c}$ Nurten Sayar ${ }^{a}$ Tugba Kemaloglu ${ }^{a}$ \\ Baris Gungor ${ }^{a}$ Betul Erer ${ }^{a} \quad$ Mehmet Yilmaz $^{b} \quad$ Ufuk Gurkan $^{a} \quad$ Nazmiye Cakmak $^{a}$ \\ Dilaver $\mathrm{Oz}^{\mathrm{a}} \quad$ Ali Nazmi Calik ${ }^{\mathrm{a}}$ Osman Bolca ${ }^{\mathrm{a}}$ \\ Departments of a Cardiology and ${ }^{b}$ Cardiovascular Surgery, Siyami Ersek Thoracic and Cardiovascular Surgery Center, \\ Istanbul, and ${ }^{\mathrm{C} D e p a r t m e n t}$ of Cardiology, Derince Training and Research Hospital, Kocaeli, Turkey
}

\section{Key Words}

Atrial electromechanical delay - Left atrial mechanical

function - Metabolic syndrome · P-wave dispersion $p=0.025$, respectively). Conclusions: This study showed that intra-atrial and interatrial EDs and Pd were prolonged and LA mechanical functions were impaired in patients with MetS.

() 2015 S. Karger AG, Basel

\section{Introduction}

Metabolic syndrome (MetS) is characterized by a cluster of cardiovascular risk factors including hypertension, abdominal obesity, insulin resistance, dyslipidemia and high levels of inflammatory factors $[1,2]$. MetS is highly prevalent in the general population and is related to an increased risk of cardiovascular disease [3, 4]. An increased risk of atrial arrhythmias has also been reported in patients with MetS $[5,6]$. The prolongation of intraatrial and interatrial electromechanical delays (EDs) and the inhomogeneous propagation of sinus impulses are well-known electrophysiologic characteristics of atria prone to fibrillation. This issue has been evaluated noninvasively by $\mathrm{P}$-wave dispersion (Pd) and tissue Doppler imaging (TDI) $[7,8]$. Recently, left atrial (LA) mechanical functions were evaluated in patients with MetS [9]. In this study, we aimed to investigate LA electrical and mechanical functions in this group of patients.

\begin{tabular}{ll}
\hline KARGER 125:s & $\begin{array}{l}\text { ( ) 2015 S. Karger AG, Basel } \\
1011-7571 / 15 / 0242-0147 \$ 39.50 / 0 \quad \text { Karger }\end{array}$ \\
$\begin{array}{l}\text { E-Mail karger@karger.com } \\
\text { www.karger.com/mpp }\end{array}$ & $\begin{array}{l}\text { Thisis an Open Access article licensed under the terms of the } \\
\text { Creative Commons Attribution-NonCommercial 3.0 Un- } \\
\text { ported license (CC BY-NC) (www.karger.com/OA-license), } \\
\text { applicable to the online version of the article only. Distribu- } \\
\text { tion permitted for non-commercial purposes only. }\end{array}$
\end{tabular}

Kazım Serhan Özcan, MD

Department of Cardiology

Derince Training and Research Hospital

TR-41000 Kocaeli (Turkey)

E-Mail serhandr@gmail.com 


\section{Subjects and Methods}

\section{Study Population}

The study population was recruited from our outpatient clinic between January 2011 and November 2012. Subjects who fulfilled the criteria for MetS according to the results of recent laboratory tests were prospectively evaluated. The population consisted of 87 patients with MetS (54 males and 33 females) and 67 control patients without MetS (40 males and 27 females). Physical examination and transthoracic echocardiography were performed, and 12lead electrocardiograms (ECGs) were obtained for each subject. Patients with a history of coronary artery disease, left ventricular (LV) wall motion abnormality, an ejection fraction of $<50 \%$, valvular heart disease, primary cardiomyopathy, bundle branch block, atrioventricular conduction anomalies on ECG, anemia, electrolyte imbalance, renal failure, pulmonary disease or poorquality echocardiographic and electrocardiographic images were excluded. Subjects with more than mild valvular regurgitation (assessed qualitatively with color Doppler imaging) and valvular stenosis of any extent were also excluded. Patients who were on medication that could affect ECG, such as antiarrhythmics, tricyclic antidepressants, beta-blockers and nondihydropyridine calciumchannel blockers, were excluded. The initial study population consisted of 98 patients with MetS; 11 patients were then excluded due to the aforementioned exclusion criteria. All patients were in sinus rhythm. MetS was defined according to the International Diabetes Federation criteria, with abdominal obesity (waist circumference $>94 \mathrm{~cm}$ for males and $>80 \mathrm{~cm}$ for females) being a feature as well as at least 2 of the following 4 parameters: hypertension (systolic blood pressure $>130 \mathrm{~mm} \mathrm{Hg}$ and/or diastolic blood pressure $>85$ $\mathrm{mm} \mathrm{Hg}$ ), a history of antihypertensive usage or hypertriglyceridemia $(\geq 150 \mathrm{mg} / \mathrm{dl})$ and treatment for this disorder, a low level of high-density lipoprotein cholesterol $(<40 \mathrm{mg} / \mathrm{dl}$ in males and $<50$ $\mathrm{mg} / \mathrm{dl}$ in females) and treatment for this disorder, a high fasting plasma glucose $(>100 \mathrm{mg} / \mathrm{dl})$ or a diagnosis of type 2 diabetes mellitus [10]. Obesity was defined as a BMI of $>30$. This study was approved by the Dr. Siyami Ersek Hospital Ethics Committee, and all patients gave their written informed consent.

\section{Conventional Echocardiography}

In all subjects, 2-dimensional, M-mode, pulsed-wave and colorflow Doppler echocardiographic examinations (iE33, Philips Medical Systems, Bothell, Wash., USA) were performed by 2 cardiologists (H.Y. and B.G.) who were blinded to the clinical details of the patients. All patients were imaged in the left lateral decubitus position. During echocardiography, a 1-lead ECG was recorded. Twodimensional and conventional Doppler examinations were obtained in the parasternal and apical views according to the guidelines of the American Society of Echocardiography [10-12]. Three consecutive cycles were averaged for every parameter. LV diameter, interventricular septal and posterior wall thickness and LV ejection fraction were measured by M-mode echocardiography. LV mass and LV mass index (LVMI) were measured. To determine LV mass, the Devereux formula was used. LVMI was calculated by dividing LV mass by body surface area and height [11]. Pulsed-wave Doppler was performed to record LV inflow velocities. Doppler echocardiographic measurements were performed according to the American Society of Echocardiography guidelines [12]. The early diastolic (E) wave and late diastolic (A) wave velocities, E/A ratio, isovolumic relaxation time and deceleration time were measured.
Assessment of LA Volumes and Mechanical Functions

LA volumes were measured echocardiographically by the biplane area-length method from the apical 2- and 4-chamber views. LA volumes were determined at three points: (1) just before mitral valve opening, i.e. maximal (Vmax), (2) at the onset of the atrial systole, i.e. at the onset of the P-wave on electrocardiography (preatrial contraction volume, $\mathrm{Vp}$ ) and (3) at the mitral valve closure, i.e. minimal (Vmin). The following LA emptying function parameters were calculated:

LA passive emptying volume $=\mathrm{Vmax}-\mathrm{Vp}$, LA passive emptying fraction = LA passive emptying volume/Vmax, LA conduit volume $=$ LV stroke volume $-($ Vmax $-V m i n)$, LA active emptying volume $=V p-V m i n, L A$ active emptying fraction $=$ LA active emptying volume $/ \mathrm{Vp}$ and LA total emptying volume $=\mathrm{Vmax}-\mathrm{Vmin}$. All volumes were indexed to body surface area and expressed in $\mathrm{ml} / \mathrm{m}^{2}$.

\section{Atrial Electromechanical Coupling and Tissue Doppler Echocardiography}

TDI was performed with transducer frequencies of 3.5-4.0 MHz by adjusting the spectral pulsed Doppler signal filters until a Nyquist limit of $15-20 \mathrm{~cm} / \mathrm{s}$ was reached, and by using the minimal optimal gain. The monitor sweep speed was set at $50-100 \mathrm{~mm} / \mathrm{s}$. In the apical 4-chamber view, the pulsed-wave Doppler sample volume was placed at the level of the LV lateral and septal mitral annuli. The atrial electromechanical coupling, i.e. the time interval from the onset of the P-wave on the surface ECG to the beginning of the A wave (PA), was obtained from the lateral mitral annulus (PAlateral), septal mitral annulus (PAseptal) and tricuspid annulus (PAtricuspid). These values were corrected for heart rate by dividing with the square root of the R-R interval [13]. The difference between corrected PAlateral and corrected PAtricuspid was defined as the interatrial ED, while the difference between corrected PAseptal and corrected PAtricuspid was defined as the intra-atrial ED [14].

The peak systolic myocardial velocity (Sm) and early and late diastolic myocardial velocities (Em and Am) were obtained at the lateral and septal mitral annuli. The global Sm, Em and Am were derived as an average from these two annular sites. All echocardiographic measurements were obtained by 2 experienced echocardiographers (H.Y. and B.G.). All echo images were analyzed independently and blinded from patients clinical characteristics by using an off-line system.

\section{P-Wave Dispersion Measurements}

All subjects underwent a standard 12-lead surface ECGs recorded at a paper speed of $25 \mathrm{~mm} / \mathrm{s}$ and a gain of $10 \mathrm{~mm} / \mathrm{mV}$ (Cardiofax GEM; Nihon Kohden Corp., Tokyo, Japan). All patients were in sinus rhythm during the analysis. The ECGs were transferred to a personal computer by scanner and then magnified $(\times 400)$ with Adobe Photoshop software (Adobe Systems, Mountain View, Calif., USA). The beginning of the P-wave was defined as the point at which the initial deflection of the P-wave crossed the isoelectric line, and the end of the P-wave was defined as the end of the deflection crossing the isoelectric line. Maximum and minimum $\mathrm{P}$-wave durations (Pmax and Pmin) were measured. The difference between the Pmax and the Pmin was defined as the Pd. Mean values for three complexes were calculated in each lead.

\section{Reproducibility}

Ten subjects in each group were randomly selected for interobserver and intraobserver variability. To test the intraobserver vari- 
ability, the Vmax, Vmin, Vp and PAlateral, PAseptal and PAtricuspid were remeasured by the same observer from the digital data using an off-line system. Interobserver variability was determined by having a second observer measure these variables from the digital data using an off-line system.

\section{Statistical Analysis}

Statistical analyses were performed using SPSS v15.0 for Windows. For evaluation of the data obtained from the study, descriptive statistical methods of mean \pm standard deviation, frequency and ratio values were used (see tables 1-3). Categorical data were compared with the $\chi^{2}$ test. Mean values of continuous variables were compared between groups using the Student t test or the Mann-Whitney U test. The relationship between parameters was determined using Pearson's coefficient of correlation. The independent correlates of atrial conduction times were assessed using multivariate linear regression analysis. The effect of clinical and echocardiographic variables, including the components of MetS, on atrial conduction times were tested using a stepwise backward elimination method. $\mathrm{p}<0.05$ was considered significant.

\section{Results}

The mean age of the patients with MetS was $32.9 \pm 5.7$ years and that of the controls was $31.6 \pm 5.3$ years. The clinical and laboratory findings of the subjects are shown in table 1 . The 2 groups were similar with regard to age, sex, a family history of coronary artery disease and smoking status ( $\mathrm{p}>0.05)$. Heart rate, BMI, waist circumference and systolic and diastolic blood pressure were significantly higher in the patient group than in the control group $(\mathrm{p}<0.05)$. Echocardiographic characteristics including the LA total and phasic volumes of subjects are shown in table 2. The heart rate of the patients during the examination was between 60 and $80 \mathrm{bpm}$. LV septum and posterior wall thickness, LVMI corrected for height and LA diameter were increased in patients with MetS (all $\mathrm{p}<$ $0.05)$. Although MetS patients had a greater mitral A velocity, LV E/Em ratio and LV Am, and a lower E/A ratio and LV Em, these measurements were within the normal range. The MetS group had a greater LA maximum $(\mathrm{p}=$ $0.03)$, preatrial contraction $(\mathrm{p}=0.001)$ and active emptying volume $(\mathrm{p}=0.001)$ than the control group, but the passive emptying fraction was lower $(\mathrm{p}=0.001)$.

The PA intervals are summarized in table 3 . The PA intervals measured on the basal LV PAlateral $(\mathrm{p}<0.001)$, PAseptal $(\mathrm{p}=0.001)$ and right ventricular PAtricuspid $(\mathrm{p}=0.008)$ were longer in the MetS patients. Patients with MetS had higher interatrial EDs than controls $(21.0 \pm 11.5$ vs. $12.3 \pm 10.4, \mathrm{p}<0.001)$ and also higher intra-atrial EDs than controls ( $10.3 \pm 6.3$ vs. $7.4 \pm 5.5, p=0003$; fig. 1a). The Pd was significantly higher in the MetS patients $(\mathrm{p}<$
Table 1. Clinical and laboratory characteristics of the study population

\begin{tabular}{lccc}
\hline & $\begin{array}{c}\text { Controls } \\
(\mathrm{n}=67)\end{array}$ & $\begin{array}{l}\text { MetS patients } \\
(\mathrm{n}=87)\end{array}$ & $\begin{array}{l}\mathrm{p} \\
\text { value }\end{array}$ \\
\hline Age, years & $31.6 \pm 5.3$ & $32.9 \pm 5.7$ & 0.128 \\
Male gender & $40(60)$ & $54(62)$ & 0.868 \\
BMI & $25.9 \pm 4.4$ & $30.9 \pm 4.9$ & $<0.001$ \\
Diabetes mellitus & $2(3)$ & $7(8)$ & 0.31 \\
Smoking & $22(33)$ & $39(45)$ & 0.139 \\
CAD family history & $24(36)$ & $46(53)$ & 0.06 \\
Obesity & $13(19)$ & $49(56)$ & $<0.001$ \\
SBP, mm Hg & $124 \pm 13$ & $132 \pm 15$ & $<0.001$ \\
DBP, mm Hg & $79 \pm 7$ & $86 \pm 9$ & $<0.001$ \\
Heart rate, bpm & $76 \pm 12$ & $82 \pm 12$ & 0.003 \\
Total cholesterol, mg/dl & $181.6 \pm 28.6$ & $196.7 \pm 32.1$ & 0.003 \\
LDL, mg/dl & $107.6 \pm 25.1$ & $119.8 \pm 28.1$ & 0.005 \\
VLDL, mg/dl & $22 \pm 10.8$ & $37.6 \pm 18.5$ & $<0.001$ \\
Components of MetS & & & \\
$\quad$ Waist circumference, cm & $90.3 \pm 9.3$ & $105.0 \pm 10.6$ & $<0.001$ \\
$\quad$ Hypertension & $14(19)$ & $52(59)$ & $<0.001$ \\
$\quad$ Fasting blood glucose, mg/dl & $89.3 \pm 6.9$ & $97.5 \pm 11.9$ & $<0.001$ \\
$\quad$ Triglycerides, mg/dl & $121.3 \pm 51.9$ & $188.9 \pm 89.2$ & $<0.001$ \\
$\quad$ HDL, mg/dl & $50.7 \pm 10.2$ & $39.3 \pm 6.3$ & $<0.001$ \\
\hline
\end{tabular}

Values are given as $\mathrm{n}(\%)$ or means $\pm \mathrm{SD}$. CAD $=$ Coronary artery disease; $\mathrm{DBP}=$ diastolic blood pressure; $\mathrm{HDL}=$ high-density lipoprotein; $\mathrm{LDL}=$ lowdensity lipoprotein; SBP = systolic blood pressure; VLDL = very-low-density lipoprotein.

0.001; fig. 1b). In a subgroup analysis, none of the aforementioned parameters was significantly different between male and females or between subjects with and without diabetes mellitus.

In the univariate correlation analysis, the interatrial ED was significantly correlated with $\mathrm{Pd}(\mathrm{r}=0.358, \mathrm{p}<$ $0.001)$, LA $\mathrm{Vp}(\mathrm{r}=0.285, \mathrm{p}<0.001)$, LA active emptying volume, $(\mathrm{r}=0.327, \mathrm{p}<0.001)$, LA passive emptying fraction $(\mathrm{r}=-0.267, \mathrm{p}=0.001)$ and $\mathrm{E} / \mathrm{A}$ ratio $(\mathrm{r}=-0.236, \mathrm{p}=$ 0.003). The intra-atrial ED was correlated with $\mathrm{Pd}(\mathrm{r}=$ $0.197, \mathrm{p}=0.014), \mathrm{LA} \mathrm{Vp}(\mathrm{r}=0.210, \mathrm{p}=0.009)$, LA active emptying volume, $(\mathrm{r}=0.239, \mathrm{p}=0.003)$ and LA passive emptying fraction $(\mathrm{r}=-0.239, \mathrm{p}=0.003)$.

In the multivariate linear regression analysis, a model adjusted for age, gender, E/A ratio, LA active emptying volume and the presence of MetS was used. The presence of MetS, LA active emptying volume and LV E/A ratio remained as the independent correlates of interatrial $\mathrm{ED}$ $\left(\mathrm{R}^{2}=0.248, \beta=0.24, \mathrm{p}=0.002 ; \beta=0.30, \mathrm{p}=0.001\right.$ and $\beta=-0.17, \mathrm{p}=0.025$, respectively).

The coefficient of variance $(\mathrm{CV})$ values for intraobserver variability were $5.7 \%$ for $V \max , 5.6 \%$ for $\mathrm{Vmin}$, 5.5\% for Vp and 5.5\% for PAlateral, 5.8\% for PAseptal and $5.4 \%$ for PAtricuspid, respectively. The CV values for 
Table 2. Comparison of echocardiographic characteristics (conventional parameters and LA total and phasic volumes) between patients with MetS and controls

\begin{tabular}{|c|c|c|c|}
\hline & Controls $(n=67)$ & MetS patients $(\mathrm{n}=87)$ & $\mathrm{p}$ value \\
\hline LV end-diastolic dimension, $\mathrm{mm}$ & $46.7 \pm 4.4$ & $47.6 \pm 4.2$ & 0.225 \\
\hline LV systolic dimension, $\mathrm{mm}$ & $28.6 \pm 4.3$ & $28.5 \pm 4.3$ & 0.920 \\
\hline Septum thickness, mm & $9.1 \pm 1.1$ & $9.8 \pm 1.2$ & 0.001 \\
\hline Posterior wall thickness, mm & $8.9 \pm 1.1$ & $9.7 \pm 1.1$ & $<0.001$ \\
\hline LV ejection fraction, \% & $68 \pm 4$ & $69 \pm 5$ & 0.570 \\
\hline LVMI, $\mathrm{g} / \mathrm{m}^{2}$ & $77.2 \pm 16.3$ & $80.8 \pm 14.3$ & 0.152 \\
\hline LVMI, g/m & $85.8 \pm 21.3$ & $98.1 \pm 20.5$ & $<0.001$ \\
\hline LA diameter, $\mathrm{mm}$ & $31.5 \pm 4.9$ & $33.9 \pm 3.7$ & 0.002 \\
\hline Mitral E velocity, $\mathrm{cm} / \mathrm{s}$ & $83.7 \pm 11.4$ & $79.5 \pm 16.6$ & 0.78 \\
\hline Mitral A velocity, $\mathrm{cm} / \mathrm{s}$ & $53.8 \pm 10.2$ & $59.0 \pm 13.8$ & 0.01 \\
\hline $\mathrm{E} / \mathrm{A}$ ratio & $1.6 \pm 0.3$ & $1.4 \pm 0.3$ & 0.001 \\
\hline Deceleration time, $\mathrm{ms}$ & $187.1 \pm 18.8$ & $191.8 \pm 27.7$ & 0.213 \\
\hline LV E/Em ratio & $5.8 \pm 1.3$ & $6.5 \pm 1.8$ & 0.004 \\
\hline $\mathrm{LV} \mathrm{Sm}, \mathrm{cm} / \mathrm{s}$ & $9.2 \pm 1.5$ & $9.2 \pm 1.4$ & 0.814 \\
\hline $\mathrm{LV} \mathrm{Em}, \mathrm{cm} / \mathrm{s}$ & $14.9 \pm 2.8$ & $12.6 \pm 2.7$ & $<0.001$ \\
\hline $\mathrm{LV} A \mathrm{~m}, \mathrm{~cm} / \mathrm{s}$ & $8.2 \pm 1.9$ & $9.6 \pm 2.1$ & $<0.001$ \\
\hline LA maximum volume, $\mathrm{ml} / \mathrm{m}^{2}$ & $22.1 \pm 4.9$ & $23.9 \pm 4.9$ & 0.03 \\
\hline LA minimal volume, $\mathrm{ml} / \mathrm{m}^{2}$ & $6.3 \pm 2.6$ & $7.0 \pm 2.8$ & 0.105 \\
\hline $\mathrm{LA} \mathrm{Vp}, \mathrm{ml} / \mathrm{m}^{2}$ & $11.8 \pm 4.2$ & $14.2 \pm 4.1$ & 0.001 \\
\hline LA passive emptying volume, $\mathrm{ml} / \mathrm{m}^{2}$ & $10.3 \pm 3.1$ & $9.9 \pm 3.6$ & 0.381 \\
\hline LA passive emptying fraction, $\%$ & $47.2 \pm 11.8$ & $41.0 \pm 11.2$ & 0.001 \\
\hline LA conduit volume, $\mathrm{ml} / \mathrm{m}^{2}$ & $22.1 \pm 3.2$ & $21.2 \pm 3.0$ & 0.09 \\
\hline LA active emptying volume, $\mathrm{ml} / \mathrm{m}^{2}$ & $5.5 \pm 2.5$ & $7.0 \pm 2.7$ & 0.001 \\
\hline LA active emptying fraction, $\%$ & $46.8 \pm 13.5$ & $50.0 \pm 13.3$ & 0.153 \\
\hline LA total emptying volume, $\mathrm{ml} / \mathrm{m}^{2}$ & $15.9 \pm 3.7$ & $17.0 \pm 3.8$ & 0.59 \\
\hline
\end{tabular}

Table 3. Electrocardiographic Pd parameters and PA findings measured by TDI

\begin{tabular}{lllr}
\hline $\begin{array}{l}\text { Electrocardiographic } \\
\text { measurements, ms }\end{array}$ & $\begin{array}{l}\text { Controls } \\
(\mathrm{n}=67)\end{array}$ & $\begin{array}{l}\text { MetS patients } \\
(\mathrm{n}=87)\end{array}$ & $\begin{array}{l}\mathrm{p} \\
\text { value }\end{array}$ \\
\hline Pmax & $88.3 \pm 11.8$ & $95.3 \pm 12.7$ & 0.001 \\
Pmin & $59.1 \pm 10.7$ & $53.3 \pm 11.2$ & 0.001 \\
Pd & $29.2 \pm 7.4$ & $41.7 \pm 10.8$ & $<0.001$ \\
PAlateral & $74.7 \pm 22$ & $89.5 \pm 18.8$ & $<0.001$ \\
PAseptal & $69.6 \pm 17.2$ & $78.9 \pm 16.6$ & 0.001 \\
PAtricuspid & $62.2 \pm 14.6$ & $68.6 \pm 14.7$ & 0.008 \\
$\begin{array}{l}\text { Interatrial ED } \\
\text { (PAlateral - PAtricuspid) }\end{array}$ & $12.3 \pm 10.4$ & $21.0 \pm 11.5$ & $<0.001$ \\
$\begin{array}{l}\text { Intra-atrial ED } \\
\text { (PAseptum - PAtricuspid) }\end{array}$ & $7.4 \pm 5.5$ & $10.3 \pm 6.3$ & 0.003 \\
\hline
\end{tabular}

interobserver variability were $5.1 \%$ for PAlateral, $6.1 \%$ for PAseptal and 5.5\% for PAtricuspid, respectively.

The intraobserver and interobserver variability for Pmax was 4.3 and $4.8 \%$, respectively. The CV values for intraobserver and interobserver variability were 4.9 and $5.1 \%$ for Pmin, respectively.

\section{Discussion}

In this study, we found that both intra-atrial and interatrial times were greater and LA mechanical function was impaired in MetS patients without atrial arrhythmia.

MetS is highly prevalent in the general population, affecting about $44 \%$ of adults according to International $\mathrm{Di}$ abetes Federation criteria [4]. It is an important and wellknown risk factor for atrial fibrillation (AF). The individual components of MetS are also risk factors for AF [15]. The mechanisms that link MetS to an increased risk of 
Fig. 1. a Box plot graph showing the comparison of interatrial ED in the MetS and control groups. Median (horizontal lines), 25th to 75th percentiles (boxes) and 95th percentiles (whiskers). b Box plot graph showing the comparison of $\mathrm{Pd}$ in the MetS and control groups. Median (horizontal lines), 25th to 75 th percentiles (boxes) and 95th percentiles (whiskers).

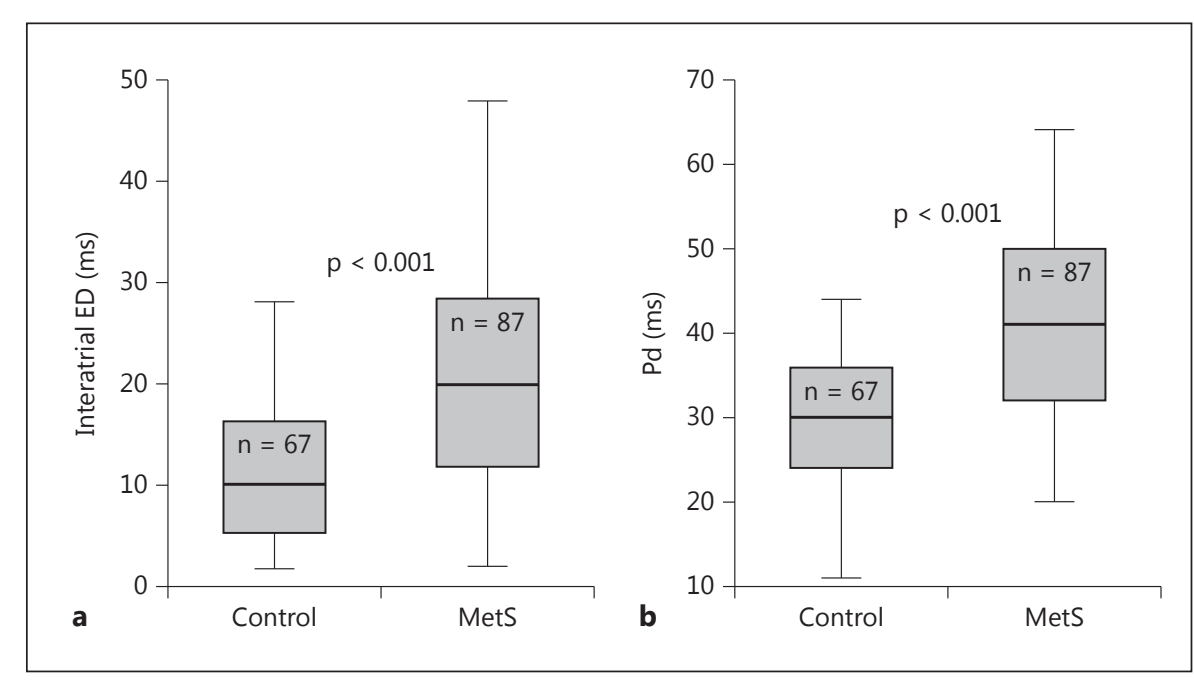

developing AF are not clearly understood [16]. Previous studies demonstrated that MetS is associated with an increase in heart rate, LV hypertrophy, impairment of diastolic function, enlargement of the LA diameter and atrial fibrosis $[5,17-20]$. In our study, we found that in the patients with MetS, LA diameter was greater and LA volumes were changed; these factors make for worse LA mechanical functions and diastolic parameters. LA functions are important determinants of LV filling, particularly when $\mathrm{LV}$ compliance is reduced. The atrium modulates ventricular filling through its reservoir, conduit and pump functions [21,22]. In this study, the MetS patients had a greater LA maximum volume, $\mathrm{Vp}$ and active emptying volume than the control group. Conversely, LA passive emptying fraction was decreased in the patients with MetS. In addition, in the multivariate regression analysis, the presence of MetS was an independent correlate of interatrial ED besides LV E/A ratio and LA active emptying volume. It has been demonstrated that LA mechanical functions are impaired in hypertensive and diabetic patients [7]. Recently, it was reported that in patients with MetS, LA maximal volume, active emptying volume and fraction are increased but LA passive emptying volume and fraction are decreased [9]. These findings suggest that atrial reserve and pump functions are impaired in patients with MetS.

Although measured diastolic function parameters were within the normal range, there was a significant difference between the 2 groups. The MetS patients had greater mitral A velocity, LV E/Em ratio, LV Am and lower LV Em and E/A ratio. These findings could indicate an early form of diastolic dysfunction. Several studies have found that patients with MetS have LV diastolic dysfunction [17-23]. LV diastolic abnormality leads to afterload increase in the LA. Thus, LA dilatation and increased LA reservoir function occur due to increased LV stiffness [9].

Atrial conduction time can be measured by both invasive and noninvasive methods [6]. Intra-atrial and interatrial conduction time prolongation and the inhomogeneous propagation of sinus impulses are known electrophysiological characteristics in patients with paroxysmal AF. It has been shown that the prolongation of atrial conduction time, measured by TDI, is an independent predictor of new onset or recurrent AF [24]. In our study, intra-atrial and interatrial EDs were prolonged, and the presence of MetS, LA active emptying volume and LV E/A ratio were independent correlates of interatrial ED. In accordance with these findings, previous studies reported that interatrial and intra-atrial conduction times are increased in patients with impaired fasting blood glucose, type 1 diabetes mellitus and MetS $[7,25,26]$.

Prolonged P-wave duration and increased Pd have been reported to be associated with an increased risk for AF [27]. We have found that Pmax and Pd were significantly higher in patients with MetS. Similarly, in another study, Pmax and Pd were significantly higher in MetS patients [28]. Several studies have demonstrated that Pmax and Pd were significantly higher in patients with diabetes mellitus and hypertension [7, 29, 30]. Therefore, in our study, we confirmed the prolongation of atrial electrical activation by using electrocardiography to measure $\mathrm{Pd}$.

The limitations of this study included patients who were not followed prospectively for arrhythmic episodes. The effects of drug therapy on study parameters could not be investigated as the medical therapy of individuals was not altered. Further studies with follow-up are necessary to investigate whether AF occurs in MetS patients with 
prolonged inter-and intra-atrial electromechanical duration. The interatrial conduction time was not investigated by invasive electrophysiological techniques. Another limitation was that the study population was relatively small.

\section{Conclusion}

This study showed that LA mechanical functions were impaired and intra-atrial and interatrial electromechanical durations prolonged in MetS patients. These findings suggest that MetS may lead to atrial electrical remodeling.
Therefore, atrial arrhythmias may develop due to impaired LA functions. Interatrial ED is a simple and highly reproducible method that can predict AF in patients with MetS. Prospective studies are needed to investigate the relation between intra-atrial and interatrial EDs, LA mechanical functions and future development of AF.

\section{Disclosure Statement}

The authors have no conflicts of interest to disclose.

\section{References}

1 Grundy SM: Metabolic syndrome pandemic. Arterioscler Thromb Vasc Biol 2008;28:629636.

2 Dagogo JS: Metabolomic prediction of diabetes and cardiovascular risk. Med Princ Pract 2012; 21:401-403.

3 Isomaa B, Almgren P, Tuomi T, et al: Cardiovascular morbidity and mortality associated with the metabolic syndrome. Diabetes Care 2001;24:683-689.

4 Gundogan K, Bayram F, Gedik V, et al: Metabolic syndrome prevalence according to ATP III and IDF criteria and related factors in Turkish adults. Arch Med Sci 2013:20;9:243-253.

5 Umetani K, Kodama Y, Nakamura T, et al: High prevalence of paroxysmal atrial fibrillation and/or atrial flutter in metabolic syndrome. Circ J 2007;71:252-255.

6 Watanabe $\mathrm{H}$, Tanabe $\mathrm{N}$, Watanabe $\mathrm{T}$, et al: Metabolic syndrome and risk of development of atrial fibrillation: the Niigata Preventive Medicine Study. Circulation 2008;117:12551260.

7 Acar G, Akcay A, Sokmen A, Ozkaya M, et al: Assessment of atrial electromechanical delay, diastolic functions, and left atrial mechanical functions in patients with type 1 diabetes mellitus. J Am Soc Echocardiogr 2009;22:732738.

8 Omi W, Nagai H, Takamura M, et al: Doppler tissue analysis of atrial electromechanical coupling in paroxysmal atrial fibrillation. J Am Soc Echocardiogr 2005; 18:39-44.

9 Yilmaz M, Ozlem AO, Akgumus A, et al: Left atrial mechanical functions in patients with the metabolic syndrome. Acta Cardiol 2013;68: 133-137.

10 Ford ES: Prevalence of the metabolic syndrome defined by the International Diabetes Federation among adults in the US. Diabetes Care 2005;28:2745-2749.

11 Lang RM, Bierig M, Devereux RB, et al: Recommendations for chamber quantification: a report from the American Society of Echocardiography's Guidelines and Standards Committee and the Chamber Quantification
Writing Group, developed in conjunction with the European Association of Echocardiography, a branch of the European Society of Cardiology. J Am Soc Echocardiogr 2005; 18:14401463.

12 Quiñones MA, Otto CM, Stoddard M, et al: Recommendations for quantification of Doppler echocardiography: a report from the Doppler Quantification Task Force of the Nomenclature and Standards Committee of the American Society of Echocardiography. J Am Soc Echocardiogr 2002;15:167-184.

13 Cui W, Roberson DA, Chen Z, et al: Systolic and diastolic time intervals measured from Doppler tissue imaging: normal values and Zscore tables, and effects of age, heart rate, and body surface area. J Am Soc Echocardiogr 2008; 21:361-370.

14 Ozer N, Yavuz B, Can I, et al: Doppler tissue evaluation of intra-atrial and interatrial electromechanical delay and comparison with $\mathrm{P}$-wave dispersion in patients with mitral stenosis. J Am Soc Echocardiogr 2005;18:945-948.

15 Tanner RM, Baber U, Carson AP, et al: Association of the metabolic syndrome with atrial fibrillation among United States adults (from the REasons for Geographic and Racial Differences in Stroke [REGARDS] Study). Am J Cardiol 2011;108:227-232.

16 Tang RB, Gao LY, Dong JZ, et al: Metabolic syndrome in patients with atrial fibrillation in the absence of structural heart disease from a tertiary hospital in China. Chin Med J (Engl) 2009;122:2744-2747.

17 de las Fuentes L, Brown AL, Mathews SJ, et al: Metabolic syndrome is associated with abnormal left ventricular diastolic function independent of left ventricular mass. Eur Heart J 2007; 28:553-559.

18 Guize L, Pannier B, Thomas F, et al: Recent advances in metabolic syndrome and cardiovascular disease. Arch Cardiovasc Dis 2008;101: 577-583.

19 de Simone G, Olsen MH, Wachtell K, et al: Clusters of metabolic risk factors predict cardiovascular events in hypertension with target- organ damage: the LIFE study. J Hum Hypertens 2007:8:625-632.

20 Nicolaou VN, Papadakis JE, Karatzis EN, et al: Impact of the metabolic syndrome on atrial size in patients with new-onset atrial fibrillation. Angiology 2007;58:21-25.

21 Prioli A, Marino P, Lanzoni L, et al: Increasing degrees of left ventricular filling impairment modulate left atrial function in humans. Am J Cardiol 1998;15;82:756-761.

22 Rossi A, Zardini P, Marino P: Modulation of left atrial function by ventricular filling impairment. Heart Fail Rev 2000;5:325-331.

23 Hwang YC, Jee JH, Kang M, et al: Metabolic syndrome and insulin resistance are associated with abnormal left ventricular diastolic function and structure independent of blood pressure and fasting plasma glucose level. Int J Cardiol 2012:23;159:107-111.

24 De Vos CB, Weijs B, Crijns HJ, et al: Atrial tissue Doppler imaging for prediction of new-onset atrial fibrillation. Heart 2009;95:835-840.

25 Ayhan S, Ozturk S, Alcelik A, et al: Atrial conduction time and atrial mechanical function in patients with impaired fasting glucose. J Interv Card Electrophysiol 2012;35:247-252.

26 Kurt M, Tanboğa IH, Karakaş MF, et al: The relationship between atrial electromechanical delay and $\mathrm{P}$-wave dispersion with the presence and severity of metabolic syndrome. Arch Turk Soc Cardiol 2012;40:663-670.

27 Dilaveris PE, Gialafos EJ, Sideris SK, et al: Simple electrocardiographic markers for the prediction of paroxysmal idiopathic atrial fibrillation. Am Heart J 1998;135:733-738.

28 Yasar AS, Bilen E, Bilge M, et al: P-wave duration and dispersion in patients with metabolic syndrome. Pacing Clin Electrophysiol 2009;32: 1168-1172.

29 Emiroglu MY, Bulut M, Sahin M, et al: Assessment of atrial conduction time in patients with essential hypertension. J Electrocardiol 2011; 44:251-256

30 Yazici M, Ozdemir K, Altunkeser BB, et al: The effect of diabetes mellitus on the P-wave dispersion. Circ J 2007;71:880-883. 